\title{
LUMINESCENCE AND TRAPPING CENTRES IN PURE AND Cd DOPED SILVER CHLORIDE CRYSTALS (*)
}

\author{
W. POLZIN, W. ASSMUS (**), F. GRANZER \\ Institut für Angewandte Physik D-6000 Frankfurt/Main, \\ Robert-Mayer-Straße 2-4, FRG
}

\begin{abstract}
Résumé. - Nous avons étudié par luminescence, thermoluminescence et RPE la nature du centre de la luminescence dans les monocristaux de chlorure d'argent purs et dopés avec $\mathrm{Cd}^{2+}$. Les résultats montrent, que le centre $\mathrm{Ag}^{2+}$ (trou autopiégé) est un centre efficace de luminescence seulement au-dessous de $T=60 \mathrm{~K}$. Aux températures au-dessus de $T=60 \mathrm{~K}$ la formation du spectre de la luminescence dépend fortement du traitement thermique des échantillons. Dans les cristaux dopés avec $\mathrm{Cd}^{2+}$ la bande de luminescence est décalée vers les grandes longueurs d'onde, peut-être par la présence de précipitations d'une phase enrichie de cadmium. En outre nos expériences ont mis en évidence, que les pièges les plus efficaces sont de petits agrégats d'argent.
\end{abstract}

Abstract. - Luminescence spectra and glow curves of differently treated pure and Cd doped $\mathrm{AgCl}$ crystals at different temperatures were compared with ESR measurements to determine the nature of the luminescence centres. It is shown that above $60 \mathrm{~K}$ the $\mathrm{Ag}^{2+}$ centre can probably not act as a radiant recombination centre. At $T>60 \mathrm{~K}$ the formation of the luminescence bands is greatly influenced by the thermal treatment of the samples. On doped crystals a Cd-rich precipitation may be responsible for a shift in the luminescence maximum. Silver specks are supposed to be the predominant traps in $\mathrm{AgCl}$ crystals.

1. Introduction. - The luminescence spectra of pure $\mathrm{AgCl}$ consist of one or two bands, a blue or blue-green and in some cases a red one. The latter is referred to the existence of $\mathrm{Ag}$ centres. The bluegreen emission at LNT peaks at values ranging from 485 to $530 \mathrm{~nm}$ as reported by several workers $[1,2,3]$, the red one between 610 and $650 \mathrm{~nm}$ $[1,4,5]$. The maximum of luminescence at LHeT or LHT is found at $510( \pm 5) \mathrm{nm}[6,7]$.

While up to the end of the sixties, but also in a newer publication [8] a so-called $\mathrm{V}$ centre (a hole trapped at a negative $\mathrm{Ag}^{+}$vacancy) has been favoured as a recombination centre responsible for the bluegreen band [1, 2], in most of the recent papers (a summary is found in [9]) the luminescence is attributed to a recombination at a $\mathrm{Ag}^{2+}$ centre (self-trapped hole) or to a localized exciton, respectively. The $\mathrm{Ag}^{2+}$ centre is assumed to be stable only during UV irradiation at $T \leqslant 50 \mathrm{~K}$ [9] or up to $77 \mathrm{~K}$ [10] and $120 \mathrm{~K}$ [11], respectively, if doped with electron traps e. $\mathrm{g} . \mathrm{Cu}^{2+}$. On the other hand luminescence of $\mathrm{AgCl}$ crystals has still been observed up to $200 \mathrm{~K}[2,11]$, where the $\mathrm{Ag}^{2+}$ should no longer exist. Therefore it seems to be worthwhile to get more information

(*) This paper is based essentially on a thesis of W. Polzin at the University of Frankfurt/M.

(**) Physikalisches Institut, Frankfurt/Main, Robert-MayerStr. 2-4. about the nature of the centres. This can be done by comparing ESR and luminescence measurements. To facilitate the interpretation of the luminescence spectra of pure crystals, additional luminescence spectra and glow curves of differently thermal treated doped and pure crystals have been recorded.

2. Experimental procedure. - 2.1 CRYSTAL PREPARATION. - The crystals used in the ESR and partly in the luminescence measurements were grown from $\mathrm{AgCl}$ powder (specpure $99.999 \%$ from Johnson Matthey and $\mathrm{Co}$, London) by means of the Bridgman method in chlorine atmosphere. The samples required for the ESR measurements were heat-treated at about $400^{\circ} \mathrm{C}$ for about two days in chlorine atmosphere and finally cooled to room temperature. Most of the luminescence experiments were carried ont with sheet crystals, individually doped up to $5000 \mathrm{ppm} \mathrm{Cd}^{2+}$. These crystals were grown by a modified sandwich method, described elsewhere $[12,13,14]$.

If necessary the samples used for the luminescence measurements were annealed in chlorine or argon atmosphere for some hours or days at $400{ }^{\circ} \mathrm{C}$, and cooled down by different rates $\left(100^{\circ} / \mathrm{min}\right.$ to $\left.10^{\circ} / \mathrm{h}\right)$. To exclude the influence of uncontrolled residual impurities, some measurements were performed with sheet crystals made of the purest available material. This $\mathrm{AgCl}$ was prepared by direct synthesis of silver 
and chlorine in vacuum with a guaranteed impurity of $0.1 \mathrm{ppm}\left({ }^{1}\right)$.

2.2 Apparatus. - The ESR measurements were performed in the $X$ band with a Varian EPR spectrometer. The variable temperature cryostat $(14 \mathrm{~K}$ up to room temperature) has been developed in our laboratory. For optical excitation the crystals were illuminated by a monochromatic light $(368 \mathrm{~nm})$ filtered from a $150 \mathrm{~W}$ xenon lamp.

For luminescence studies the sample were excited with steady UV radiation from a $45 \mathrm{~W}$ high pressure mercury lamp with stabilized lightarc. The light with an intensity of $1.6 \times 10^{15}$ quantas $/ \mathrm{cm}^{2} . \mathrm{s}$, was filtered to isolate the $365 \mathrm{~nm}$ emission line.

The luminescence is passed through a Zeiss monochromator M 4 Q III to a photomultiplier tube (HTV R 500) sensitive from 180 to $750 \mathrm{~nm}$. To prevent entry of excitation radiation into the detecting system, UV absorption filters have been placed between the cryostat and the monochromator.

All luminescence measurements were performed with the optical Oxford continuous flow cryostat system CF 104 in a temperature range from 10 to $200 \mathrm{~K}$.

The luminescence spectra are corrected with respect to the spectral sensitivity of the photomultiplier. By reason of the low intensity the glow curves were normally recorded integrally or using only some colour filters.

3. Results. - 3.1 ESR MEASUREMENTS. - The crystals to be measured were mounted in the cryostat

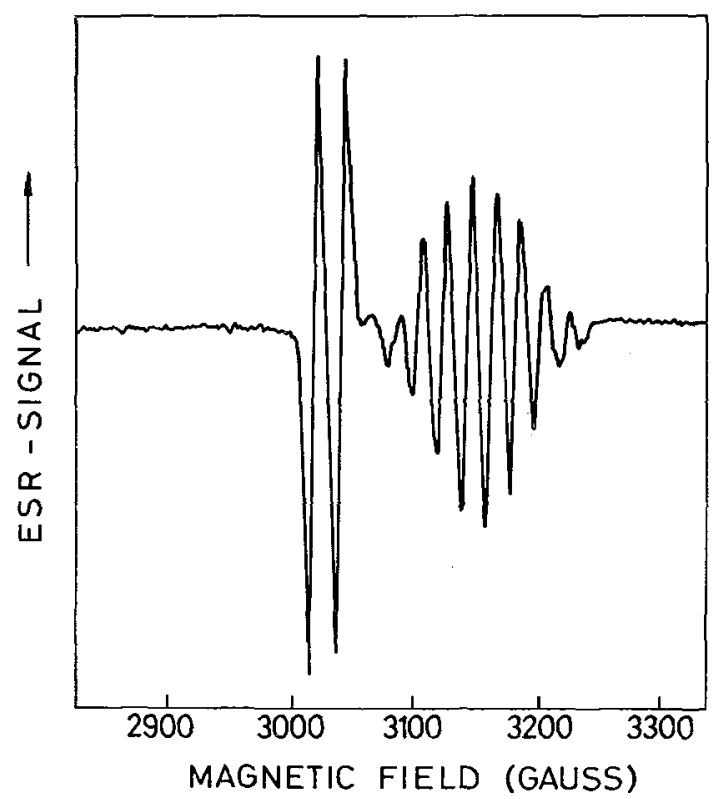

FIG. 1 - ESR spectrum of the $\mathrm{Ag}^{2+}$ centre in $\mathrm{AgCl}$ with $H /[100]$.

(1) The authors are indebted to Prof. Malinowski, Institute of Physical Chemistry, Sofia/Bulgaria for furnishing the suprapure material. with one of the $\langle 100\rangle$ orientations parallel to the external magnetic field. Without irradiation no ESR spectrum at $T=20 \mathrm{~K}$ was observed. When the samples were irradiated with UV light, the ESR spectrum shown in figure 1 is obtained. It is the characteristic spectrum of the $\mathrm{Ag}^{2+}$ centre. If the UV light is switched off, the $\mathrm{Ag}^{2+}$ further remains stable at a temperature ranging from 20 to $37 \mathrm{~K}$ (Fig. 2, curve 1).

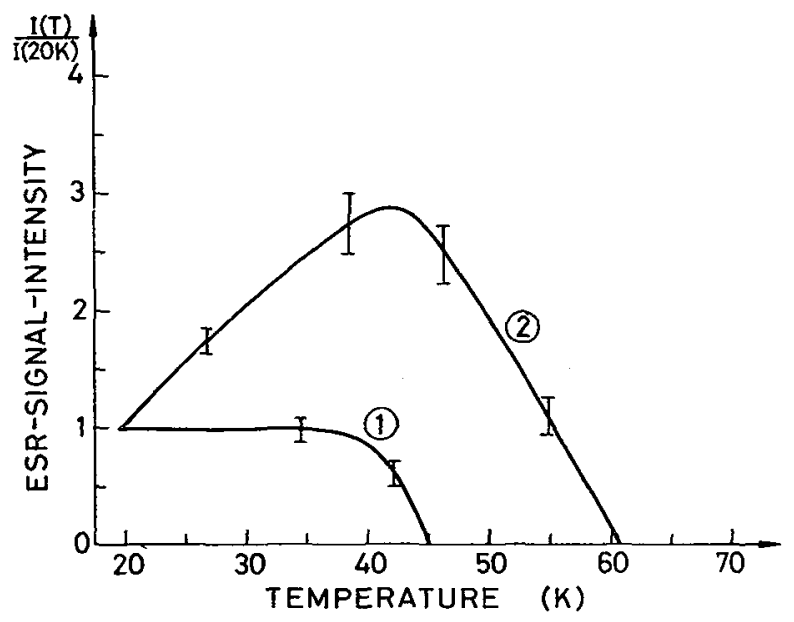

Fig. 2. - The change of ESR signal intensities of the $\mathrm{Ag}^{2+}$ centre as a function of temperature : curve 1 after switching off the UV excitation at LHT, curve 2 with UV irradiation.

Above $37 \mathrm{~K}$ the intensity of the ESR lines and therefore the number of the $\mathrm{Ag}^{2+}$ centres quickly decreased. Above $45 \mathrm{~K}$ they disappeared completely. If the sample was continuously UV irradiated once more the ESR spectrum of the $\mathrm{Ag}^{2+}$ centre was observed again up to $60 \mathrm{~K}$.

If the crystal is slowly warmed up from $20 \mathrm{~K}$ during the UV irradiation (Fig. 2, curve 2) the concentration of the $\mathrm{Ag}^{2+}$ centres at first strongly increases, peaks at $40 \mathrm{~K}$ and decreases again. Above $60 \mathrm{~K}$ the ESR signal has disappeared. The strong increase in intensity during the warming up can only be attributed to an increase of the concentration of the $\mathrm{Ag}^{2+}$ centres by the simultaneous UV irradiation. It cannot be caused by saturation effects at low temperatures, for these ought to result in a corresponding increase of curve 1 in figure 2 (not irradiated sample !).

The ESR signal at $T>60 \mathrm{~K}$ disappears either by the transition of the $\mathrm{Ag}^{2+}$ in a state not observable with ESR measurements (e. g. a dynamic Jahn-Teller effect) or by electron-hole recombination. To decide whether the first or the second process takes place, two further measurements were carried out. The second process must be preferred, because after cooling the crystal from $60 \mathrm{~K}$ to $20 \mathrm{~K}$ within $3 \mathrm{~min}$ without $\mathrm{UV}$-irradiation it was not possible to reproduce the spectrum of the $\mathrm{Ag}^{2+}$ centre, and furthermore by investigations of crystals containing copper. Without UV irradiation the spectrum of the $\mathrm{Cu}^{2+}$ centre was observed at $T=20 \mathrm{~K}$. When the crystals 
were excited with UV light, the $\mathrm{Cu}^{2+}$ centres, being effective electron traps, were destroyed and the typical spectrum of the $\mathrm{Ag}^{2+}$ centre appeared. Above $T=60 \mathrm{~K}$ the spectrum of the $\mathrm{Cu}^{2+}$ centre could be observed again, while the spectrum of the $\mathrm{Ag}^{2+}$ centre disappeared.

These results point to the fact that $\mathrm{Ag}^{2+}$ centres are not stable above $60 \mathrm{~K}$. Further UV irradiation and warming up give rise to a strong ESR signal above $130 \mathrm{~K}$ that might be caused by the formation of photolytic silver.

3.2 LUMINESCENCE SPECTRA. - 3.2.1 Pure crystals. - In the temperature range where the $\mathrm{Ag}^{2+}$ centre is stable, i. e. $T \leqslant 60 \mathrm{~K}$, and independent of the thermal treatment of the crystals the luminescence maxima were found at $514 \pm 3 \mathrm{~nm}$, the largest corresponding to $T=45 \mathrm{~K}$ (see Fig. 3). Above $60 \mathrm{~K}$

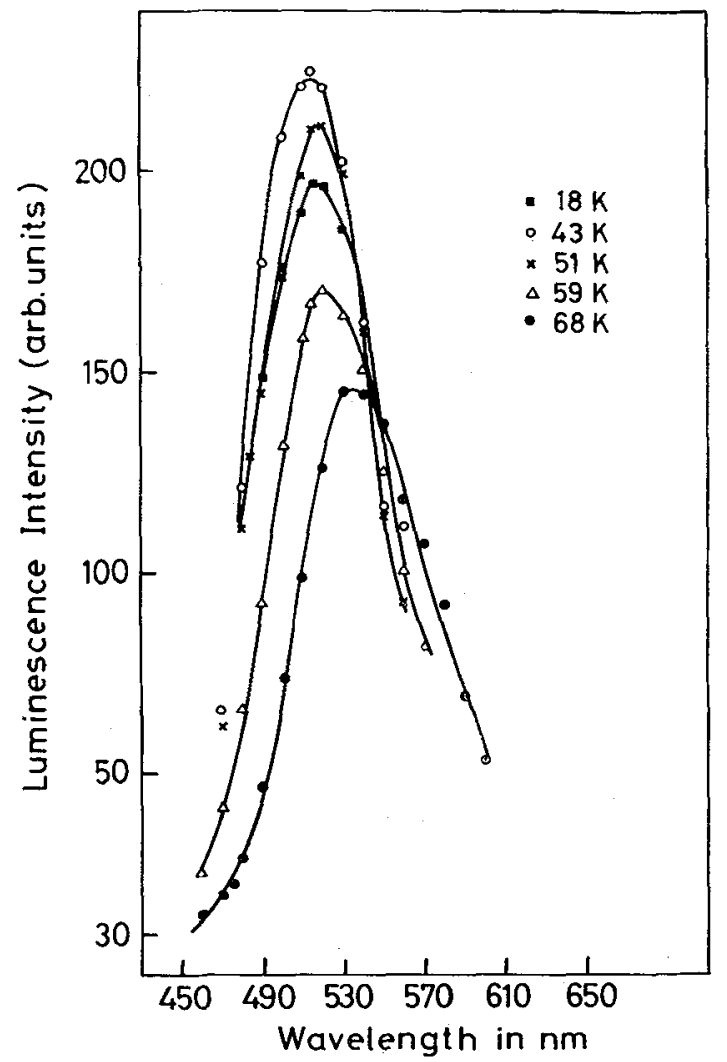

FIG. 3. - Luminescence spectra of an $\mathrm{AgCl}$ sheet crystal at different temperatures.

the luminescence phenomena markedly depend on the thermal history of the crystals. The position of the luminescence maximum of $\mathrm{AgCl}$ crystals varies in the range from 485 to $530 \mathrm{~nm}$ at LNT. As shown in figure 4 it is possible to cover the whole range by only varying the annealing conditions. Annealing in argon always favoured the formation of the band at $485 \mathrm{~nm}$ and sometimes of a more or less weak band in the red $(620 \mathrm{~nm})$ above LNT (Fig. 5). With crystals annealed in chlorine the $485 \mathrm{~nm}$ band appears only at elevated temperatures (about $130 \mathrm{~K}$ ).
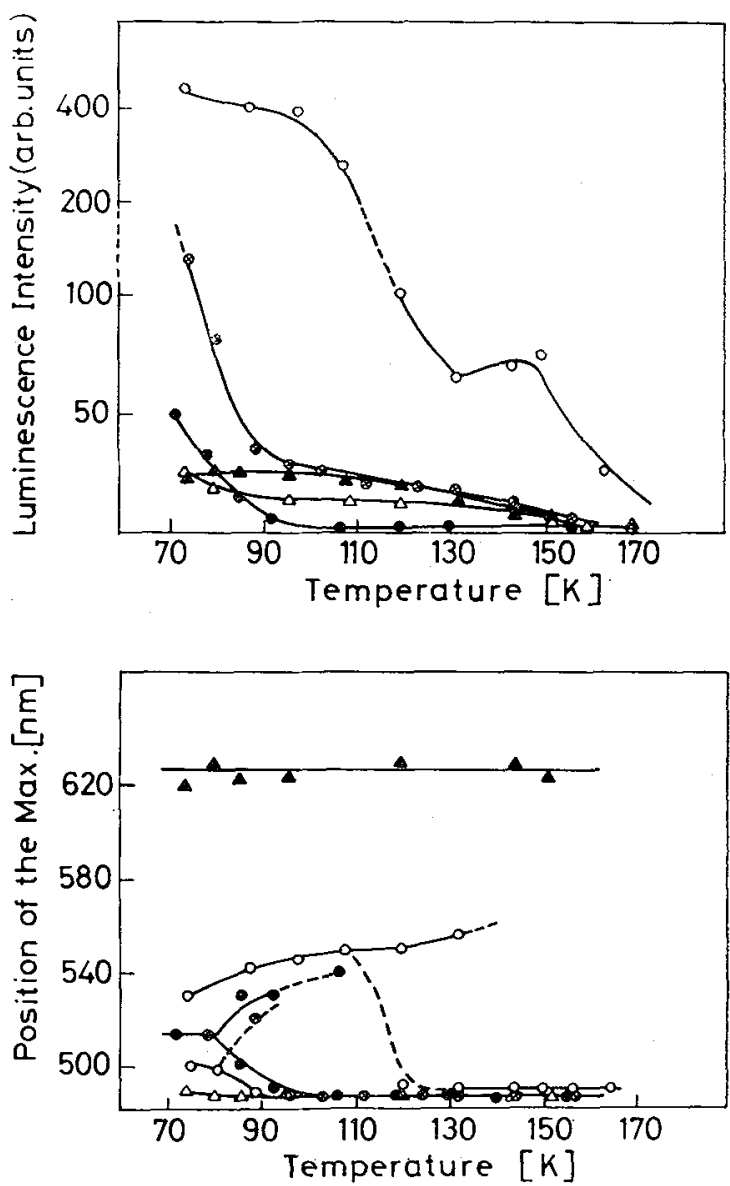

FIG. 4. - Luminescence intensity and position of the luminescence maxima of differently treated $\mathrm{AgCl}$ crystals with respect to the temperature (above LNT) : $\otimes$ untreated, $O$ chlorine annealed, - argon annealed $(20 \mathrm{~h}), \triangle \operatorname{argon}$ annealed $(30 \mathrm{~h})$; $\lambda \approx 485 \mathrm{~nm}, \Delta$ argon annealed $(30 \mathrm{~h}) \lambda \approx 620 \mathrm{~nm}$.

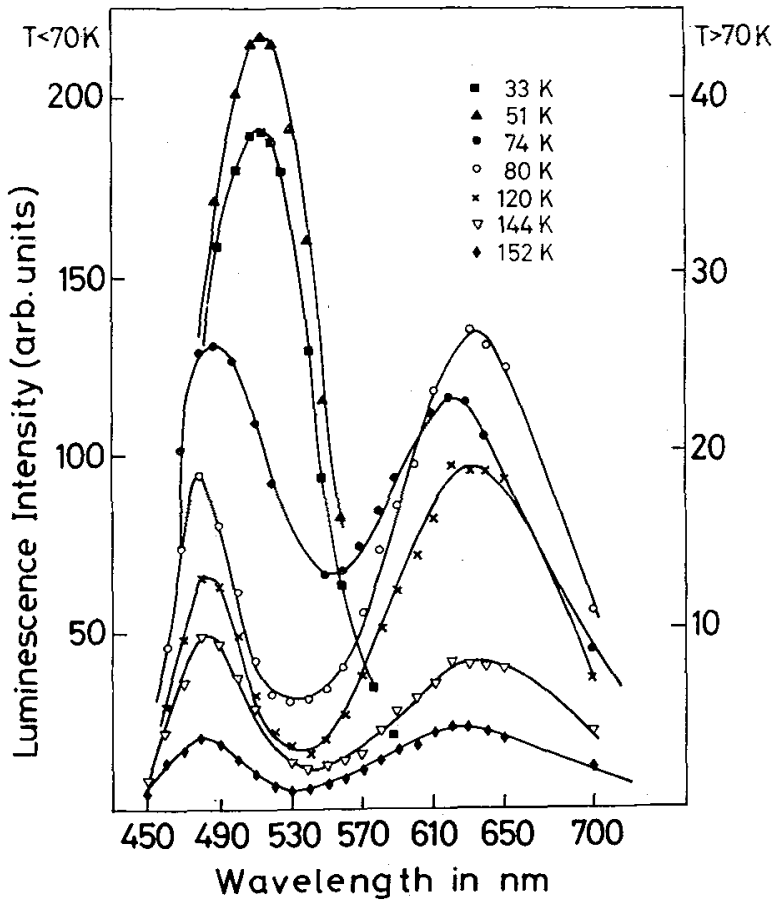

Fig. 5. - Luminescence spectra of an $\mathrm{AgCl}$ sheet crystal, annealed in argon $(30 \mathrm{~h})$ at different temperatures. 
The luminescence intensity of chlorine annealed crystals is always substantially larger than the intensity of samples which had been treated in argon. A higher concentration of negatively charged vacancies ( $\mathrm{Ag}_{\square}^{-}$) and consequently $\mathrm{V}$ centres could in principle be received by annealing and subsequent quenching pure crystals. But the great influence of the annealing treatment on luminescence properties doesn't permit a decision if $\mathrm{V}$ centres really participate in the luminescence process [15].

3.2.2 Cd doped crystals. - Doping with divalent cations, like $\mathrm{Cd}^{2+}$, always increases the concentration of negatively charged vacancies in the $\mathrm{Ag}^{+}$sublattice of AgCl. Depending on the amount of doping and the temperature, these vacancies are either isolated or associated with $\mathrm{Cd}^{2+}$-ions forming a neutral $\left[\mathrm{Cd}^{2+} \mathrm{Ag} \overline{0}\right]$-complex. Regardless if either a $\mathrm{V}$ centre or the $\left[\mathrm{Cd}^{2+} \mathrm{Ag}_{\square}^{-}\right]$associate is assumed to serve as a luminescence centre [16], in both cases the addition of Cd must result in an increase of the luminescence yield. The same argument holds for a model, developed by Kanzaki [6] who proposed an exciton localized at a cation vacancy to be responsible for the luminescence.

Our observations and results however are in strong contradiction to these expectations (see also [17]) for the following 3 reasons :

1. With increasing Cd-doping from 0 to $200 \mathrm{ppm}$ the luminescence intensity decreases and substantially increases after exceeding the solubility limit which is reported to be about $300 \mathrm{ppm}$ [18] (Fig. 6).

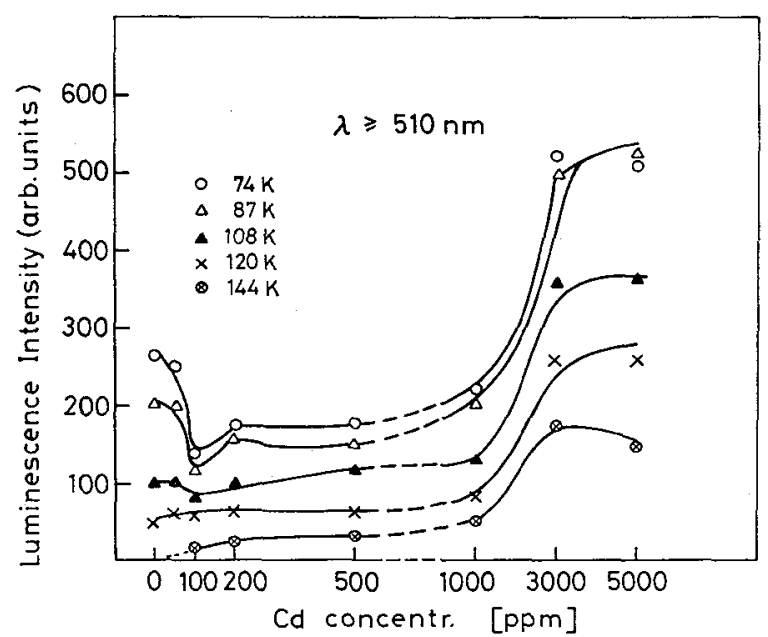

FIG. 6. - Luminescence intensity at different temperatures with respect to $\mathrm{Cd}$-doping.

2. If crystals heavily doped with $5000 \mathrm{ppm} \mathrm{Cd}$ and annealed in chlorine were quenched from $400{ }^{\circ} \mathrm{C}$ to LNT (in order to suppress precipitation !) they give less luminescence intensity than the same crystals when cooled down slowly (in order to facilitate precipitation!).
3. Doping shifts the luminescence maximum from 514 to $523 \mathrm{~nm}$ at LHT and from 520 to $540 \mathrm{~nm}$ at LNT, respectively (compare $[6,16,19]$ ).

These results indicate that the precipitation of a $\mathrm{Cd}$-rich phase in the $\mathrm{AgCl}$ matrix seems to be responsible for the luminescence phenomena in $\mathrm{Cd}$-doped crystals.

3.3 Glow Curves. - The lifetime of the $\mathrm{Ag}^{2+}$ is very much influenced by the existence of electron traps and, as already mentioned in 3.1, the ESR signal at $T \leqslant 40 \mathrm{~K}$ remains stable for some minutes without continuing the UV irradiation.

Therefore it seems worthwhile to get more information about the nature of such electron traps and their energetic levels in the forbidden bandgap of $\mathrm{AgCl}$. Thermoluminescence. i. e. the recording of glow curves, is one of the mostly used methods in order to reveal the spectrum of electron traps in crystals and has been applied to $\mathrm{AgCl}$ by several workers $[7,8,20]$.

This paper is only involved with the important findings necessary to be able to discuss the nature of the luminescence centres or electron traps. More details will be published elsewhere.

In our thermoluminescence experiments with $\mathrm{AgCl}$ crystals, having the same properties as those used in ESR and luminescence measurements, glow curves were obtained by at first irradiating the samples at $T=10 \mathrm{~K}$ or in several cases at LNT with UV light until all traps have been filled. i. e., when the luminescence has reached its saturation value. After a short dark period the crystals were warmed up at the constant heating rate of $4 \mathrm{~K} / \mathrm{min}$ and the luminescence generated during the warming up was recorded.

A typical glow curve of a pure as grown crystal is shown in figure 7 . These glow curves generally exhibit 12 to 15 glow peaks in the range from 25 to $160 \mathrm{~K}$. Some of these peaks have been found in the literature. Immediately after switching off the UV excitation a very pronounced decay of the luminescence intensity was observed which was followed by a weak afterglow of at least several minutes (compare [6, 21]). Such a behaviour is always observed when electrons were thermally released from traps in an energy range corresponding to a temperature of $10 \mathrm{~K}$. The afterglow phenomena were similar if the sample was irradiated at LNT. With some samples the afterglow could be observed over a period of more than one hour. Figure 7 shows a glow peak at $77 \mathrm{~K}$. Therefore the strong phosphorescence at LNT must be closely connected with the recombination of electrons, released from traps corresponding to a temperature of $77 \mathrm{~K}$, with luminescence centres which evidently are stable more than one hour. In a similar way Fatuzzo [21] explains the formation of the glow peak on $\mathrm{AgBr}$ crystals at $77 \mathrm{~K}$. 


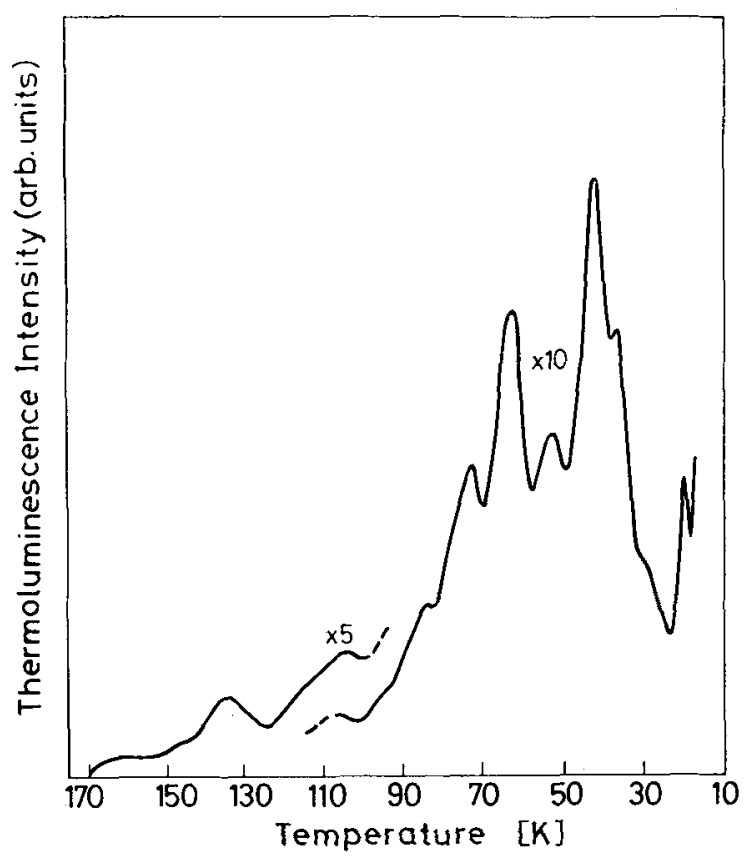

FIG. 7. - Glow curve of a pure as grown $\mathrm{AgCl}$ crystal; UV excitation at $10 \mathrm{~K}$; dark period before heating up $\approx 2 \mathrm{~min}$; heating rate $\approx 4 \mathrm{~K} / \mathrm{min}$.

The thermal treatment of the crystals also strongly affects the intensity and number of glow peaks. In figure $8 a$ and $b$ glow curves of chlorine, annealed $(a$, curve 1) and argon annealed (b, curve 1$)$ crystals are plotted for comparison. Both samples were at first heat-treated for the same time in chlorine atmosphere before annealing them again. The peak about $37 \mathrm{~K}$ could be detected with all samples, while the additional maxima at higher temperatures were found especially on argon annealed crystals. If the samples were not heat-treated in chlorine after their production, their glow curves have more than the tenfold intensity and at higher temperatures new glow peaks arise (see Fig. 7). A short annealing process in argon increases this effect, but an extended annealing period, favouring the formation of the $485 \mathrm{~nm}$ luminescence band, causes a strong decrease (Fig. $8 b$, curve 3 ) of the glow intensity.

From these results it may be concluded that the measured glow curves can certainly not be due to electrons released from traps which are connected with dislocations or grain boundaries, for the number of these defects must be independent of the annealing atmosphere. This was confirmed by further measurements on annealed and quenched or deformed crystals. Residual impurities also have no influence : a sample with $0.1 \mathrm{ppm}$ impurity can have more intense glow peaks than a sample with $10 \mathrm{ppm}$.

From these results it becomes evident, that traps, wich are responsible for the glow peaks are of intrinsic nature. According to their strong dependence on the annealing conditions, $\mathrm{Ag}_{\mathrm{n}}$ aggregates seem to be the prevailing electron traps.

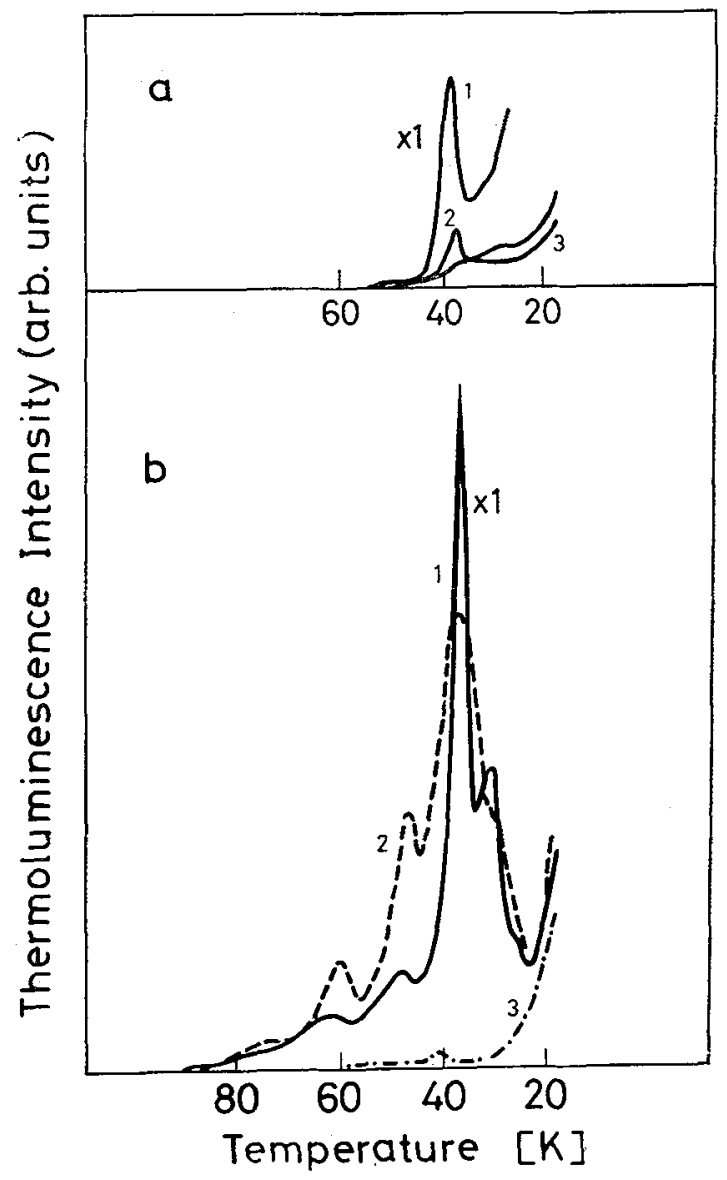

FIG. 8. - Glow curves of chlorine $a$ ) and argon $b$ ) annealed crystals : a) curve 1 : first measurement ; curve 2 second measurement; curve 3 : third measurement ; b) curve 1 : first measurement; curve $2:$ second measurement; curve $3:$ glow curve of a crystal exhibiting luminescence maxima at 485 and $620 \mathrm{~nm}$ at LNT (compare fig. 5).

This statement is further supported by the following observations :

1. If after the irradiation at LHT or LNT the sample is warmed up to $70 \mathrm{~K}$ and $140 \mathrm{~K}$, respectively and then cooled down and if this procedure is repeated once or twice (this is called a second or third measurement), the luminescence intensity of the principal maxima is always less than after a first measurement. (Fig. 8a, curve 2 and 3 .)

A similar result was mentioned by Jeltsch [22] in thermo stimulated currents (TSC) measurements. Sometimes the glow peaks at the high temperature side are altogether more intense in comparison with the first measurement. (Fig. 8b, curve 2.)

This behaviour could be referred to a redistribution or enlargement of the $\mathrm{Ag}_{\mathrm{n}}$ centres, caused by the UV irradiation and thermal release of electrons during the warming up period.

Results reported by Michrina and Cooper [23] on $\mathrm{AgBr}(\mathrm{J})$ crystals were interpreted in the same way.

2. The influence of $\mathrm{Cd}$ additions only results in a modified $\mathrm{Ag}$ distribution, possibly according to a 
heterogenous nucleation of the $\mathrm{Ag}_{\mathrm{n}}$ centres at the precipitations of a Cd-rich phase. This has no influence on the position of the glow peaks.

In order to clear up the nature of the luminescence centres one has to answer the following question: are the luminescence centres, responsible for the formation of the glow curve the same as the centres causing the luminescence spectra ? Analysing of the glow curves by suitable filters shows that at least at temperatures ranging from $20-100 \mathrm{~K}$ the wavelength of the glow light equals that of the steady-state luminescence light.

To get the energetic spectrum of the electron traps, glow curves were evaluated using the method proposed by Rao [24] and - if possible - by the initial rise method [25]. The single glow peaks between 20 and $160 \mathrm{~K}$ correspond to energy values lying in the energy range of 0.015 to $0.4 \mathrm{eV}$ or 0.03 to $0.8 \mathrm{eV}$, by assuming first or second order kinetics, respectively.

4. Discussion. - The ESR studies at $T<37 \mathrm{~K}$ point to $\mathrm{a} \mathrm{Ag}^{2+}$ centre which is stable even after stopping the UV excitation. On the other hand the luminescence intensity immediately decreases by several tenth of powers (compare $[6,10]$ ) after switching off the UV light. Assuming the $\mathrm{Ag}^{2+}$ as a luminescence centre, the number of the centres therefore must decrease in the same way after stopping the UV excitation. A weak afterglow however still remains over a period of several minutes. From these results it follows that only these $\mathrm{Ag}^{2+}$ centres contribute to the ESR spectrum where the recombination of electrons and holes is prevented by the capture of electrons in stable traps. The number of luminescence centres, responsible for the slow decay of the luminescence is therefore negligible with respect to the number of $\mathrm{Ag}^{2+}$ centres, stabilized by electron traps. This is in good agreement with the comparative small glow intensity at $T<35 \mathrm{~K}$. At $T>37 \mathrm{~K}$ the $\mathrm{Ag}^{2+}$ centre disappears if the sample is not excited simultaneously with UV-light. This may be due to a release of electrons from their traps and their subsequent recombination with the $\mathrm{Ag}^{2}+$ centre, or their transition in a state not observable with ESR measure-' ments. As already stated, the second possibility could be ruled out, because a new cooling does not regenerate the ESR spectrum without simultaneous UV irradiation. This result is further in good agreement with the occurrence of strong glow peaks at $T \approx 40 \mathrm{~K}$. Therefore it is safe to assume that the electron traps responsible for the glow curves - namely $\mathrm{Ag}_{\mathbf{n}}$ centres - at least contribute to the stabilization of the $\mathrm{Ag}^{2+}$ centres. M. Höhne and M. Stasiw [26] also mentioned a possible participation of $\mathrm{Ag}_{\mathrm{n}}$ centres as electron traps in ESR measurements. Moreover the lack of $\mathrm{Ag}_{\mathrm{n}}$ centres could be the reason for the fact that some workers could detect the $\mathrm{Ag}^{2+}$ centres on pure crystal only by optical absorption and not by ESR measurement.
With continuous UV irradiation the $\mathrm{Ag}^{2+}$ centre could be observed up to $60 \mathrm{~K}$ in the ESR spectrum. The results on copper doped crystals indicate an increasing mobility of the holes at this temperature which causes the spectrum to disappear [9]. Owing to the measuring method the lifetime of the $\mathrm{Ag}^{2+}$ cannot exceed $\approx 100 \mathrm{~ms}$. On the other hand some samples showed a strong afterglow lasting more than $60 \mathrm{~min}$ at LNT. Moreover during the subsequent warming up period further electrons released from the traps were able to recombine radiationally with the luminescence centres (glow curves !) and finally the wavelength of the steady-state luminescence agrees well with that of the glow light: thus all these results indicate that above $60 \mathrm{~K}$ luminescence is not caused by a recombination of electrons with $\mathrm{Ag}^{2+}$ centres. Only in the temperature range $T<60 \mathrm{~K}$ the $\mathrm{Ag}^{2+}$ centre could act as a luminescence centre.

Another centre observed by Ulrici [27] with optical absorption measurements may be responsible for the luminescence at $10<T \leqslant 120 \mathrm{~K}$ as well. This centre is not detectable with ESR, can be destroyed by irradiation with red light and is stable up to $120 \mathrm{~K}$. It is not characterized in more detail.

At $T>130 \mathrm{~K}$ both the shape of the ESR signal and the formation of the luminescence bands at 485 or $620 \mathrm{~nm}$ seem to indicate that the $\mathrm{Ag}_{\mathrm{n}}$ aggregates act as luminescence centres at these temperatures. This is further supported by our observations on argon annealed crystals and by S. I. Golub [28] and K. W. Schalimowa [4] who observed the same bands when heating up the crystals in air or doping the samples with silver. Thus the different luminescence maxima at LNT can be caused by a superposition of a silver band and another band produced by the yet unknown centre observed by Ulrici.

The shift of the luminescence maximum from $514 \mathrm{~nm}$ (pure crystals) to $523 \mathrm{~nm}$ (Cd doped samples) at LHT indicates the formation of a new luminescence centre. As already proved in 3.2.2 the $\left[\mathrm{Cd}^{2+} \mathrm{Ag}_{\square}\right]$ associates cannot work as a radiant recombination centre. The decrease of intensity with increasing $\mathrm{Cd}$ additions up to the solubility limit could be attributed to both the $\left[\mathrm{Cd}^{2+} \mathrm{Ag}_{\square}^{-}\right]$associate and the isolated Ag- operating as competing radiationless recombination centre for electrons and holes.

Further increasing the doping concentration of $\mathrm{Cd}$ starts the precipitation of a Cd-rich phase in the $\mathrm{AgCl}$ matrix. At the same time (see 3.2.2) the luminescence intensity markedly increases. Thus it may be assumed that the precipitation itself or the boundaries (interfaces) between the precipitations and the surrounding $\mathrm{AgCl}$ matrix act as luminescence centres.

This conception however seems to be in contradiction to the findings that the new luminescence maximum rises already at concentrations of $\sim 100 \mathrm{ppm} \mathrm{Cd}$ at LNT where the solubility limit of $\mathrm{AgCl}$ probably is not yet exceeded. On the other hand all crystals 
examined so far have a high density of dislocation (about $10^{8} / \mathrm{cm}^{2}$ ). Thus, even at low Cd concentration, precipitation may be facilitated by heterogeneous nucleation along the dislocation lines. This mechanism is supported by studies of the small angle X-ray scattering $\left({ }^{2}\right)$ performed on the same crystals which point at a cylindric shape of the precipitation.

If one assumes the $\mathrm{Ag}^{2+}$ to be the luminescence centre in doped crystals too, then, from he experimental results, at $T<60 \mathrm{~K}$ the formation of the $\mathrm{Ag}^{2}+$ may be favoured by the precipitation. If the $\mathrm{Ag}^{2+}$ is located near a phase boundary or near a $\mathrm{Ag}^{+}$vacancy the crystal field of the $\mathrm{Ag}^{2+}$ centre may

(2) Wentz, M., Granzer, F., to be published. be disturbed and so could possibly change the corresponding energy level. This would result in the shift of the luminescence maximum as observed in the spectra.

At $T>60 \mathrm{~K}$, where the $\mathrm{Ag}^{2+}$ seems to be unstable another centre influenced by the precipitation - perhaps that proposed by Ulrici - must be responsible for the luminescence. But one cannot rule out the possibility that the phase boundary itself acts as a recombination centre in the whole temperature range.

Acknowledgment. - This work has been supported by the Deutsche Forschungsgemeinschaft and partly by the German Ministerium f. Bildung und Wissenschaft (St. Sch. 504). The authors would like to thank Mr. Th. Wendnagel for furnishing most of the samples used for the luminescence measurements.
[1] Beneš, J. et al., Phys, Status Solidi 3 (1963) 52

[2] Wiegand, D., Phys. Rev. 113 (1959) 52.

[3] Aline, G. P., Phys. Rev. 105 (1957) 406.

[4] Schalimowa, K. W., Belkina, A. V., Zh. Eksperim. $i$. theor. Fiz. 21 (1951) 326.

[5] Farnell, G. C., Burton, P. C., Hallama, R., Phil, Mag. 41 (1950) 159 and 545.

[6] Kanzaki, H., Sakuragi, S., Solid. State Commun. 9 (1971) 1667.

[7] SMITH, G., Phys. Rev. 140A (1965) 221

[8] Aramu, F., Maxia, V., Spano, G., J. Lumin. 9 (1974) 104.

[9] Stasiw, O., Phys. Status Solidi (a) 61 K (1974) 115.

[10] MarquardT, C. L., Williams, R. T., Kabler, N. M., Solid State Commun. 9 (1971) 2285.

[11] Zhitnikov, R. A. et al., Sov. Phys. Solid State 15 (1973) 645.

[12] Clark, P. V. Mc D., Mrtchell, J. W., J. Photogr. Sci. 4 (1956) 1 .

[13] Granzer, F., Schopper, E., Henig, G., Schott, J. U., Dardat, K., Wendnagel, Th., HaAse, G., Zörgiebel, F., 8th Conference on Nuclear Photography and Visual Detectors, Bukarest (1972).

[14] Wendnagel, Th., Report given at the 3rd Anniversary of the German Gesellschaft für Kristallwachstum und Kristallzüchtung eV., Hamburg (1973).

\section{References}

[15] Riesenfeld, J., Photogr. Sci. Eng. 17 (1973) 213.

[16] Orlovskaya, N. A. et al., Int. Congr. of Phot. Sci., Dresden 9 (1974).

[17] Moser, F., Van Heyningen, R. F., Lyu, S., Solid. State Commun. 7 (1969) 1609.

[18] Zierold, K., Wentz, M., Granzer, F., J, Physique Colloq. 34 (1973) C 9-415.

[19] Sonoike, S., Akimoto, V., J. Phys. Sac. Japan 16 (1961) 658.

[20] Gordon, A., Phys. Rev. 122 (1961) 748.

[21] Fatuzzo, E., Oggion,, R., Photogr. Sci. Eng. 17 (1973) 319.

[22] JeLtSCH, E., Z. Phys. 154 (1959) 601.

[23] Michrina, B. P., Cooper, W., Photogr. Sci. Eng. 18 (1974) 512.

[24] Rao, D. R., Phys. Status Solidi 22 (1974) 337.

[25] Garlick, G. F. J., Gibson, A. F., Proc. Phys. Soc. 60 (1948) 574

[26] Höhne, M., Stasiw, M., Phys. Status Solidi 28 (1968) 247.

[27] Ulricr, W., Phys. Status Solidi 40 (1970) 557.

[28] Golub, S. I., Orlovskaya, N. A., Bull. Acad. Sci. USSR, Phys. Ser. 25 (1961) 379.

\section{DISCUSSION}

M. Georgiev. - Do your results agree with those of Höhne and Stasiw on the ESR of the $\mathrm{Ag}^{++}$-center in $\mathrm{AgCl}$ ? Have you observed a corresponding signal from a $\mathrm{AgBr}$ crystal ?

W. PolzIN. - Our results are in agreement with those of Stasiw and Höhne. Unfortunately we have not performed any measurements on $\mathrm{AgBr}$.

C. L. Marquardt. - 1) We have observed hole self trapping $\left(\mathrm{Ag}^{++}\right)$at temperatures as high as $80 \mathrm{~K}$ in transient optical experiments. This would not be in disagreement with your thermal stability measurements with excitation light on and off if the thermal instability around $50 \mathrm{~K}$ actually corresponds to the onset of mobility of the self trapped hole.

2) Is not the role of $\mathrm{Ag}$ metal in stabilizing $\mathrm{Ag}^{++}$ merely that of providing deep electron traps which prevents recombination?

W. Polzin. - 1) I agree, that there must be no contradiction between your and our result concerning the temperature range of the thermal stability of the $\mathrm{Ag}^{2+}$-centre.

2) In our paper it was explicitely assumed, that the stabilization of $\mathrm{Ag}^{2+}$-centres is due to the presence of silver aggregates acting as electron traps of a deepness between 0.015 and $0.8 \mathrm{eV}$. 